\title{
Toll-Like Receptors in Cystic Fibrosis: Impact of Dysfunctional microRNA on Innate Immune Responses in the Cystic Fibrosis Lung
}

\author{
Sebastian F. Vencken Catherine M. Greene \\ Department of Medicine, Royal College of Surgeons in Ireland, Dublin, Ireland
}

\section{Key Words}

MicroRNA · Cystic fibrosis · Toll-like receptors · Lung

\begin{abstract}
Toll-like receptors (TLRs) are a class of pattern recognition receptors that are particularly expressed in the sentinel and epithelial cells in the body, including the lung. They are central players in the innate immune system in response to microbial infection, and are the triggers of a complex pathway network that both promotes the inflammatory response and influences the adaptive immune response. These pathways are transiently and finely tuned by cellular factors, including a cell's microRNA response program. MicroRNAs are small, non-coding RNAs that specifically regulate gene expression. In this article, we review the disease-specific microRNA regulatory network of cystic fibrosis, a debilitating and ultimately fatal disease and, specifically, its effect on TLR signalling.

๑) 2016 S. Karger AG, Basel
\end{abstract}

\section{Introduction}

Innate immunity is a rapid, short-lived process that occurs in response to invading micro-organisms. Originally considered non-discriminatory, the innate immune system is actually highly specific. This property is due to pattern recognition receptors (PRRs), a collection of receptors with key roles in innate immunity. Conserved microbial structures are recognised by PRRs. Toll-like receptors (TLRs) are a major subclass of PRRs that can detect and discriminate specific molecular microbial patterns, induce intracellular signalling that leads to the activation of transcription factors that control innate immune responses and they also promote adaptive immunity. How, where and when TLRs are expressed can have a major impact on the effectiveness of an individual's innate immune response. So mechanisms that control the expression of TLRs and their signalling intermediates fine-tune this process. MicroRNAs (miRNAs) are posttranscriptional regulators of protein expression that affect every aspect of human biology. In this review, the consequences of dysfunctional miRNA expression on TLR-mediated effects in the cystic fibrosis (CF) lung are outlined and explored.

\section{TLRs and TLR Signalling Pathways}

TLRs are a family of germ-line encoded transmembrane pattern recognition receptors belonging to the TLR and interleukin (IL)-1/IL-18 receptor superfamily [1]. Unlike the IL-1/IL-18 receptors, which have immuno-

\section{KARGER}

E-Mail karger@karger.com

www.karger.com/jin
(C) 2016 S. Karger AG, Basel

$1662-811 \mathrm{X} / 16 / 0086-0541 \$ 39.50 / 0$
Dr. Sebastian F. Vencken

Department of Medicine, Royal College of Surgeons in Ireland

Smurfit Building, Beaumont Hospital

IE-Dublin 9 (Ireland)

E-Mail sebastianvencken@ rcsi.ie 
Table 1. Selected major PAMPs and DAMPs

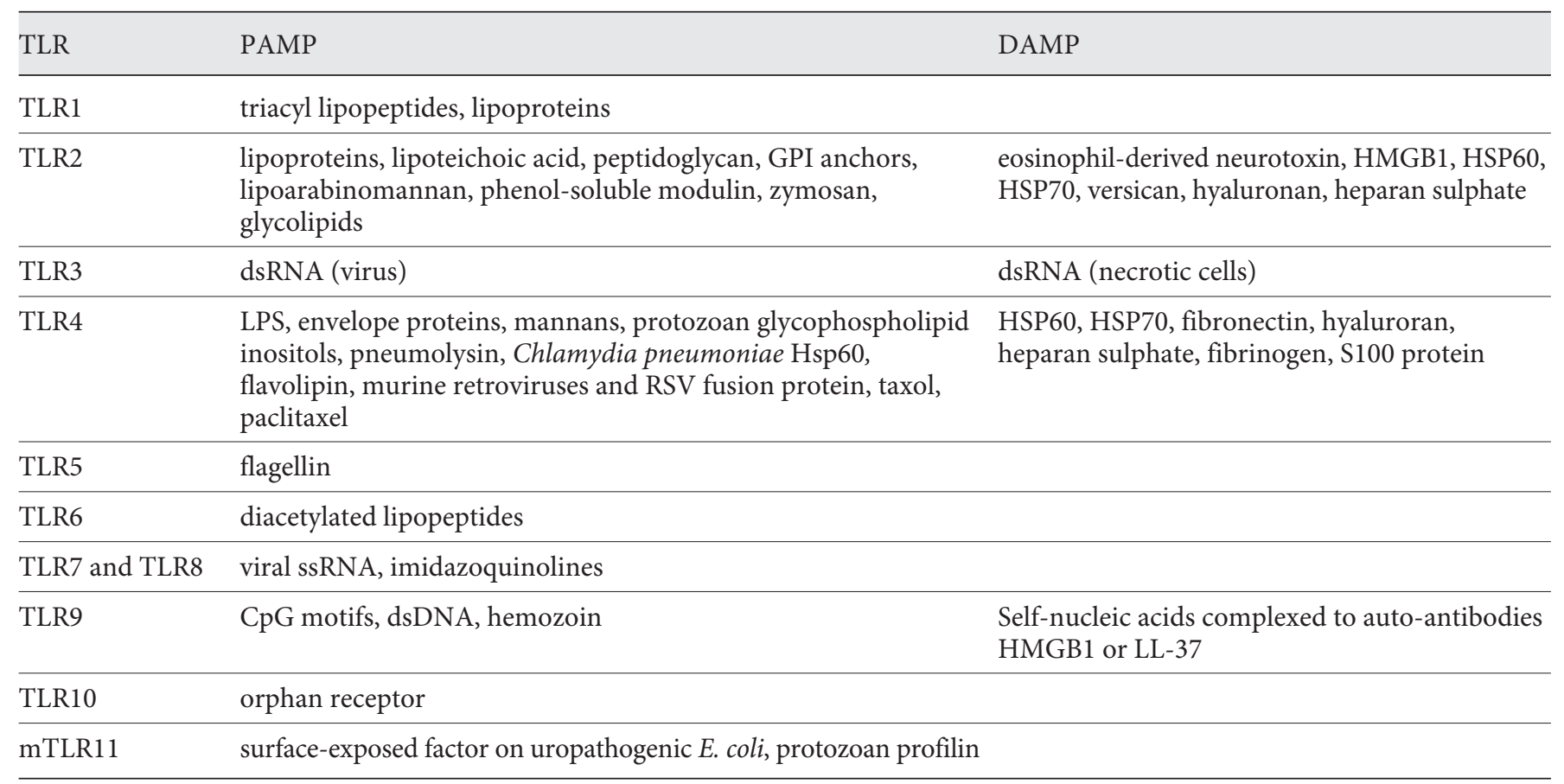

globulin-like domains located extracellularly, TLRs display leucine-rich repeats on the cell surface which are required for ligand recognition. The intracellular domains of this family of proteins are more highly conserved and all carry a critical TLR-IL-1R (TIR) domain, first described by Heguy et al. [2], which facilitates intracellular signal transduction via TIR-TIR interactions between TLRs and specific intracellular adaptor proteins. There are at least 11 TLRs encoded in the human genome, although hTLR11 is truncated due to a premature stop codon mutation and unlike its murine counterpart, mTLR11, cannot transduce signals induced by uropathogenic Escherichia coli [3]. On phagocytic cells such as dendritic cells and macrophages, TLR1, TLR2, TLR4, TLR5, TLR6 and TLR11 are expressed on the cell surface, whereas TLR3, TLR7, TLR8 and TLR9 are located in the endosome.

All TLRs can recognise and discriminate a specific set of microbial-derived ligands, commonly referred to as pathogen-associated molecular patterns (PAMPs). Engagement of TLRs with these motifs leads to the activation of pro-inflammatory and innate immune gene expression via the activation of the transcription factors $\mathrm{NF \kappa B}, \mathrm{AP} 1$ and interferon-regulatory factors (IRFs). In addition, TLRs can also be activated by a set of endoge- nous host factors that act as signals that something is awry - these are the so-called damage- or danger-associated molecular patterns (DAMPs). Table 1 is a list of common PAMPs and DAMPs.

The immediate first step that occurs following activation of any TLR by its cognate ligand is the association of that TLR's TIR domain with the TIR domain in the adaptor proteins MyD88, TIRAP (also called MAL), TRIF (or TICAM-1) or TRAM (or TICAM-2). Apart from TLR3, all TLRs can signal directly via MyD88. TLR3 can engage directly with TRIF, as can TLR4 indirectly via TRAM; TIRAP can be utilised by TLR2 and TLR4 to engage with MyD88. A fifth, related protein exists, called SARM. This is a TIR domain-containing protein that acts as a negative regulator of TRIF-dependent TLR signalling [4].

The 2 major intracellular pathways that are activated by TLRs are referred to as the MyD88-dependent and TRIF-dependent pathways (fig. 1; reviewed by Greene [1]). Engagement of a TLR with MyD88 leads to the activation of mitogen-activated protein kinases (MAPKs) and the transcription factor NFKB, via an intracellular signalling cascade involving the sequential activation of IL-1 receptor-associated kinase 4 (IRAK4), IRAK1 and IRAK2, and the E3 ubiquitin ligase TRAF6. TRAF6 and 


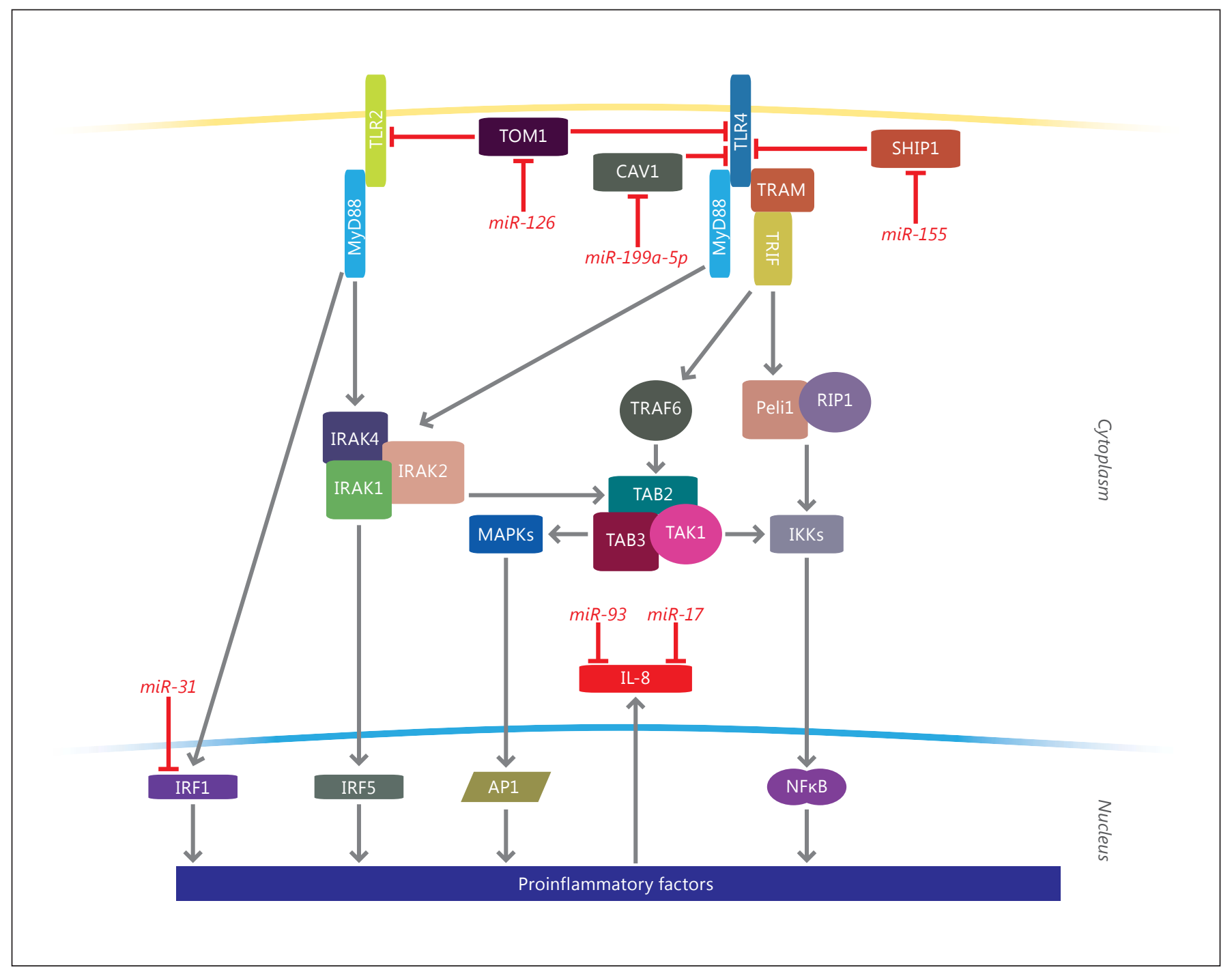

Fig. 1. MyD88- and TRIF-dependent TLR signalling pathways influenced by miRNAs in CF. Peli1 = Pellino-1.

IRAK1 undergo lysine63-linked ubiquitination via the ubiquitin-conjugating enzymes Ubc13 and Uev1. Next, the regulatory proteins $\mathrm{TAB} 2$ and $\mathrm{TAB} 3$ bind leading to activation of TAK1, the kinase that phosphorylates and activates the $\beta$ subunit of the IKK complex. Nuclear localisation sequences on NFKB become exposed as a result of the phosphorylation, ubiquitination and degradation of IkB proteins by the proteasome. Translocation of the NFkB dimer into the nucleus facilitates the binding of this transcription factor to its consensus sequences in gene promoters followed by their transactivation. The MAPKs ERK1, ERK2, p38 and JNK, which can induce AP1 activation and influence translation, are phosphorylated by TAK1. Finally, IRFs 5 and 7 can be activated by TRAF6 leading to the induction of proinflammatory cytokines and type I interferons, respectively.

The TRIF pathway (also frequently referred to as the MyD88-independent signalling pathway) commonly leads to activation of the IRF transcription factors and upregulation of type I interferons. TRAF3 is activated by TRIF and the signal is transduced via IKKi and TBK1, culminating in the phosphorylation and activation of IRF3. TRIF can also activate NFkB either via TRADD, Pellino-1 and RIP1 or via TRAF6, leading to NFאB and MAPK activation as described above. 


\section{TLRs in the CF Lung}

The first reports describing TLR expression in primary and transformed CF airway epithelial cells provided evidence that TLRs 1-10 and MyD88 are expressed and functional in CF airway epithelia [5-7]. These findings complemented previous work performed in non-CF bronchial epithelial cells, which showed that mRNAs for all TLRs are expressed by tracheal, bronchial and alveolar type II airway epithelial cells and that the receptors are exposed on the mucosal surface of the airway, presumably in order to facilitate activation by exposure to PAMPs. TLR2 is the predominant TLR expressed on the surface of bronchial epithelial cells in vivo, whereas TLR3, TLR4 and TLR5 reside mainly intracellularly or display only low-level surface expression [7-9]. Interestingly, whilst TLR9 resides in endosomes in phagocytic cells, it has been shown to be expressed on the cell surface of primary and transformed differentiated airway epithelial cells. Of note, stimulation of airway epithelial cells with microbial factors such as respiratory syncytial virus, flagellin and Pseudomonas aeruginosa can enhance the expression of TLR2, TLR4 and TLR5 on the epithelial cell surface, respectively [9-11]; this has relevance for the CF lung when considering the molecular effects of viral and bacterial infective exacerbations. People with CF are frequently colonised with fungal species such as Aspergillus. Whether conidial dsRNA can induce interferon- $\beta$ via activation of TLRs in CF airway epithelial cells, as has been demonstrated in non-CF cells, is not known [12]. Alternatively, the mechanism involved may be similar to what occurs in murine macrophages that display chitin-induced activation of TLR2 [13].

There have been other reports on TLR expression and function in CF airway epithelium. For example, John et al. $[14,15]$ reported that TLR4 is displayed at very low levels on the apical surface of CF airway epithelial cells in vivo; unsurprisingly, the cells fail to respond strongly to LPS stimulation and consequently have weaker than normal MyD88- and TRIF-dependent signalling. TLR5 mediates inflammatory responses to flagellin-expressing Burkholderia cepacia, B. cenocepacia and P. aeruginosa. In CF airway epithelial cells, inhibition of TLR5 abolishes $P$. aeruginosa-induced IL- 6 production, and CF adults with a dysfunctional TLR5 $1174 \mathrm{C}>\mathrm{T}$ SNP have an improved body mass index $[16,17]$.

Due to microbial infection, the CF lung is a PAMPrich milieu. Ongoing inflammation and protease-mediated damage generates DAMPs. In addition to these classical TLR agonists, the CF lung also contains a selection of factors that can indirectly activate TLRs. For example, heme, which may be present in the lumen of the CF lung due to cleavage of hemoglobin in microbleeds by neutrophil elastase and Pseudomonas-derived proteases, can activate TLR signalling and pro-inflammatory gene expression via EGFR [18]. Neutrophil elastase itself can also indirectly activate TLR 4 via a mechanism involving meprin and/or TACE, TGFa and EGFR. This has been shown to lead to exaggerated IL-8 and mucin gene expression [19, 20].

\section{miRNAs and TLR Signalling in the Lung}

Several miRNAs target key points along the TLR signalling pathways, effecting a large degree of epigenetic control. These relationships between particular miRNAs and TLR pathway members have been characterised in resident white blood cells, in pulmonary tissue/cell lines, or both. The TLR pathways themselves also transcriptionally regulate miRNAs, in some instances forming feedback loops. The synergistic action between TLR signalling and miRNA regulation has previously been extensively reviewed $[21,22]$. It is thought that miRNAs control the TLR pathways in response to inflammatory stimuli, regulating their strength and timing during the inflammatory response. Furthermore, miRNAs can control the cellular location of the pathway elements and enable cross talk with other physiological pathways $[21,22]$. Most miRNAs are upregulated by the activation of TLR signalling, suggesting that those that form feedback loops can protect against hyperstimulation of TLRs and aid inflammatory resolution $[21,22]$. However, the role here of miRNAs is selective and timed, as targeting by TLR pathway-miRNAs can have both pro- and anti-inflammatory properties.

miRNAs have many roles in the development and maintenance of the lung and its immune system. Several of these also have been linked to TLR signalling pathways. miR-21 is strongly upregulated in mouse lung upon exposure to E. coli LPS and in allergic airway inflammation [23, 24]. This has also been found in other tissues and cell lines exposed to various inflammatory stimuli, and it was discovered that miR-21 can be induced through TLR4/ MyD88 activation of NFKB or AP1 while also negatively regulating TLR signalling by inhibiting MyD88 and IRAK1 [25-27]. Although not yet specifically characterised as such, it is likely that these feedback loops between miR-21 and TLR signalling pathways also exist in airway leukocytes and epithelial cells. 
miR-155, the most commonly described miRNA in the innate immune system, is upregulated in mouse lungs and lung epithelial cells upon inflammatory and mechanical insult [28-31]. Although not fully explored in the lungs, miR-155 is likely induced by NFKB and inhibited by STAT3 transcription factors through several TLRs (TLR2, TLR3, TLR4 and TLR9) and cytokines (notably inhibited by anti-inflammatory IL-10) [22, 32, 33]. Generally considered a pro-inflammatory miRNA, miR-155 can directly target the negative regulators of TLR4 signalling, SHIP1 and SOCS1, an observation also documented in the lung and bronchial epithelium [29, 31]. However, miR-155 can also suppress TLR signalling at key points of convergence along the pathways, indicating opposing functions. These include the targeting of the pro-inflammatory signal tranducers IKK, IкBa, MyD88 and TAB2 [34-37].

miR-146a is a highly documented anti-inflammatory miRNA with several critical targets in TLR signalling pathways [38]. It is highly expressed in the lung and is further induced in lung macrophages, epithelial cells and basal tissues upon their exposure to inflammagens such as LPS and pro-inflammatory cytokines, but also injury [39-44]. miR-146a induction can be mediated through TLR signalling (specifically through TLR2, TLR3, TLR4 and TLR5) and is directly induced by NFKB $[21,22,45]$. In the lung, miR-146a has been found to ameliorate the inflammatory response by directly targeting critical proinflammatory members of TLR signalling, including IRAK1 and TRAF6 $[40,44,45]$. The TLR signalling targets of miR-146a validated in other tissues and cell lines include TLR4 and IRAK2, making them likely additional targets in the lung [46].

miR-21, miR-155 and miR-146a are the best-characterised miRNAs involved in TLR signalling; however, in recent years, many more miRNAs have been linked with these pathways. Table 2 contains a list of miRNAs discovered to be involved in TLR signalling in the lung.

\section{miRNAs and CF}

Since our publication showing a role for miRNAs in $\mathrm{CF}$ for the first time, several miRNAs have been found to be pathologically dysregulated in the CF lung compared to non-CF lungs [47]. miRNA dysregulation in CF has recently been extensively reviewed by McKiernan and Greene [48] and Sonneville et al. [49]. Numerous deregulated miRNAs have now been identified to be specifically deregulated in the lungs of people with CF, with predict-
Table 2. Functional TLR-related miRNA-target relationships in the lung

\begin{tabular}{|c|c|c|}
\hline miRNA & Target molecules & Reference(s) \\
\hline miR-155 & $\begin{array}{l}\text { SHIP1 } \\
\text { SOCS1 }\end{array}$ & $\begin{array}{l}{[29,58]} \\
{[31]}\end{array}$ \\
\hline $\operatorname{miR}-21$ & $\begin{array}{l}\text { IL-12 } \\
\text { PDCD4 }\end{array}$ & $\begin{array}{l}{[23,24]} \\
{[59]}\end{array}$ \\
\hline $\operatorname{miR}-146 a$ & $\begin{array}{l}\text { IRAK1 } \\
\text { TRAF6 } \\
\text { IRF5 }\end{array}$ & $\begin{array}{l}{[40,44,45]} \\
{[40,44,45,60]} \\
{[60]}\end{array}$ \\
\hline miR-132 & $\begin{array}{l}\mathrm{ACHE} \\
\text { FOXO3 }\end{array}$ & $\begin{array}{l}{[61]} \\
{[33]}\end{array}$ \\
\hline miR-19a & $\begin{array}{l}\text { STAT3 } \\
\text { SOCS1 }\end{array}$ & $\begin{array}{l}{[62]} \\
{[63]}\end{array}$ \\
\hline miR-203 & TAK1 & {$[64]$} \\
\hline miR-212 & $\mathrm{ACHE}$ & {$[65]$} \\
\hline $\operatorname{miR}-29 c^{1}$ & TNFAIP3 & {$[66]$} \\
\hline $\operatorname{miR}-199 a-5 p$ & CAV1 & {$[55]$} \\
\hline miR-9 & PPP2R5D & {$[67]$} \\
\hline miR-17 & $\begin{array}{l}\text { IL-8 } \\
\text { STAT3 }\end{array}$ & $\begin{array}{l}{[51]} \\
{[68]}\end{array}$ \\
\hline miR-20a & STAT3 & {$[68]$} \\
\hline miR-106b & STAT3 & {$[68]$} \\
\hline miR-221 & TNFAIP3 & {$[69]$} \\
\hline miR-365 & IL-6 & {$[70]$} \\
\hline miR-106a & IL-10 & [71] \\
\hline miR-15a & TLR1 & {$[72]$} \\
\hline miR-16 & TLR1 & {$[72]$} \\
\hline $\operatorname{miR}-124$ & $\begin{array}{l}\text { TLR6 } \\
\text { MyD88 } \\
\text { TRAF6 } \\
\text { TNFa }\end{array}$ & $\begin{array}{l}{[73]} \\
{[73]} \\
{[73]} \\
{[73]}\end{array}$ \\
\hline miR-302 & IRAK4 & {$[74]$} \\
\hline miR-7 & PIK3R3 & {$[75]$} \\
\hline miR-126 & TOM1 & {$[47]$} \\
\hline miR-31 & IRF-1 & {$[53]$} \\
\hline miR-93 & IL-8 & {$[52]$} \\
\hline
\end{tabular}

CF-specific miRNA-target interactions and related studies are in bold type. Instead of inhibition, miR-29c protects TNFAIP3 from degradation. 
ed and validated targets important to the disease's pathophysiology [47-49]. As elaborated in the next section, most miRNA-target relationships in CF have been linked to the immune system and inflammation, but some have also been studied in the context of cellular dysfunction, such as endoplasmic reticulum stress and ion conductance. Endoplasmic reticulum stress is a major feature of CF airway epithelial cells and a component of this is the unfolded protein response program. miR-221, which is upregulated in CF bronchial epithelial cells and bronchial brushings, has recently been linked to this program through its downregulation of ATF6, a key component of the unfolded protein response and a major responder to endoplasmic reticulum stress [50].

\section{miRNAs, CF and TLRs}

A number of dysregulated miRNAs functionally affect the innate immune system in the CF lung. Only a few publications address miRNA regulation of, or by, TLR signalling pathways in CF specifically. Nonetheless, recent discoveries have begun to address the complex role of miRNAs in the innate immune system of the CF lung. The first discovery of pathological miRNA dysregulation in CF involved the targeting of TOM1, which was upregulated in CF bronchial brushings, by miR-126, which was downregulated [47]. TOM1 is a negative regulator of TLR2, TLR4 and IL-1R1 signalling, and its chronic upregulation in the CF lung is suggested to be a compensatory measure to limit runaway inflammation. In separate studies, miR-17 and miR-93, both of which are downregulated in CF bronchial epithelia, have been found to target IL-8 [51, 52]. IL-8, the major neutrophil chemotactic factor, is the most important pro-inflammatory chemokine in the CF lung and is highly upregulated in the $\mathrm{CF}$ lung environment. In both studies, miR-17 and miR93 were found to be downregulated by Pseudomonasinduced infection in bronchial epithelial cell lines, contributing to IL- 8 overexpression. This mechanism could potentially be expanded to include a wider gamut of chronic infectious diseases.

Weldon et al. [53] found a significant increase of cathepsin $\mathrm{S}$ in the bronchoaveolar lavage fluid of CF patients over that from non-CF lungs. Together with neutrophil elastase, this potent protease and pro-inflammatory mediator is thought to be an important exacerbator of lung tissue destruction and inflammation. They also found that miR-31, which is decreased in CF bronchial brushings, inhibits the transcription of cathepsin S by tar- geting its transcription factor IRF1. IRF1 is frequently part of TLR signalling as it can be activated directly downstream from TLR2 [54]. However, in this study, cathepsin $S$ transcription was not found to be dependent on P. aeruginosa infection [53]. Although not further investigated in this study, TLR2 activation and subsequent cathepsin Stranscription by IRF1 could still potentially exist through infection by Staphylococcus aureus, a potent trigger of TLR2 signalling and a common resident pathogen in CF lungs [54].

Zhang et al. [55] recently discovered the aberrant underexpression of caveolin 1/CAV1 by miR-199a-5p overexpression in CF macrophages and lung tissue. CAV1 is a negative regulator of TLR4 signalling and is normally upregulated upon LPS-induced activation of TLR4, which is facilitated through the concurrent downregulation of miR-199a-5p. In CF macrophages, a failure of miR-199a$5 p$ to downregulate in response to LPS stimulation results in the persistent underexpression of CAV1 and consequential TLR4 hyperstimulation. The authors found that this is caused by aberrant PI3K-AKT signalling unique to CFTR-deficient macrophages, and possibly lung tissue. They further postulated that the lack of signalling functions by CFTR, otherwise present in non-CF macrophages, contribute to this. They have also shown that dysfunctional regulation of miRNA expression, directly linked to mutant CFTR, can contribute to the symptomatic manifestation of this disease, opening up additional routes for therapy. Likewise, the CFTR mutation can upset other TLR-related, self-regulatory effector miRNAs. Bhattacharyya et al. [56] have shown that the crucial feedback effector of TLR signalling, miR-155, is elevated in CFTR-mutant bronchial epithelial cells compared to in CFTR-corrected cells. They provide evidence that the unique underexpression of the ARE-mRNA destabilising protein, TTP, in CF cells, results in the chronic stabilisation and thus overexpression of pro-inflammatory miR155.

These are a few important examples of miRNA regulation of TLR signalling in CF. The miRNA-target relationships that form part of the TLR pathways in CF are highlighted in table 2 (in bold type) and in fig. 1.

The number of miRNAs implicated with TLR signalling in CF is increasing. This opens up avenues for targeted therapies, possibly in the form of miRNA modulators such as mimics or miRNA inhibitors. Upon delivery to the lung, these miRNA modulators could suppress or activate the desired elements of the TLR pathways. However, due to the dual nature of many miRNAs as both proinflammatory and anti-inflammatory agonists, the risk of 
undesirable pathway activation should be taken into account. Nonetheless, miRNA modulation of TLR signalling may be an attractive anti-inflammatory option, and the first attempts at this have already been made [57].

\section{Concluding Remarks}

TLR signalling is a critical component of host defence, but its dysregulation can be harmful in chronic inflammatory diseases such as CF. The concerted effort to elucidate the TLR network has been given a new dimension with the discovery of the miRNA regulation of TLR sig- nalling. Both advantageous and disadvantageous effects of miRNAs on TLR pathways in CF have been explored only recently. Their further investigation will provide new insights into TLR signalling as well as the potential for developing novel diagnostics and therapeutics.

\section{Acknowledgements}

C.M.G.'s group gratefully acknowledges funding by the Health Research Board, the European Respiratory Society and GlaxoSmithKline, the Science Foundation Ireland, the National Children's Research Centre, the Alpha One Foundation and the Cystic Fibrosis Foundation.

\section{References}

1 Greene CM (ed): Toll-Like Receptors in Diseases of the Lung. Bentham Science Publishers, 2012. http://www.eurekaselect.com/ 99512/volume/1 (last accessed 22 December 2015).

-2 Heguy A, Baldari CT, Macchia G, Telford JL, Melli M: Amino acids conserved in interleukin-1 receptors (IL-1Rs) and the Drosophila toll protein are essential for IL-1R signal transduction. J Biol Chem 1992;267:26052609.

3 Lauw FN, Caffrey DR, Golenbock DT: Of mice and man: TLR11 (finally) finds profilin. Trends Immunol 2005;26:509-511.

4 O’Neill LAJ, Fitzgerald KA, Bowie AG: The Toll-IL-1 receptor adaptor family grows to five members. Trends Immunol 2003;24:286-290.

$\checkmark 5$ Hauber H-P, Tulic MK, Tsicopoulos A, Wallaert B, Olivenstein R, Daigneault $\mathrm{P}$, et al: Toll-like receptors 4 and 2 expression in the bronchial mucosa of patients with cystic fibrosis. Can Respir J 2005;12:13-18.

6 Greene CM, Carroll TP, Smith SGJ, Taggart CC, Devaney J, Griffin S, et al: TLR-induced inflammation in cystic fibrosis and non-cystic fibrosis airway epithelial cells. J Immunol 2005; 174:1638-1646.

$>7$ Muir A, Soong G, Sokol S, Reddy B, Gomez MI, Van Heeckeren A, et al: Toll-like receptors in normal and cystic fibrosis airway epithelial cells. Am J Respir Cell Mol Biol 2004; 30:777-783.

$>8$ Guillot L, Medjane S, Le-Barillec K, Balloy V, Danel C, Chignard M, et al: Response of human pulmonary epithelial cells to lipopolysaccharide involves Toll-like receptor 4 (TLR4)-dependent signaling pathways: evidence for an intracellular compartmentalization of TLR4. J Biol Chem 2004;279:27122718.

$\checkmark 9$ Adamo R, Sokol S, Soong G, Gomez MI, Prince A: Pseudomonas aeruginosa flagella activate airway epithelial cells through asialoGM1 and toll-like receptor 2 as well as toll-like receptor 5. Am J Respir Cell Mol Biol 2004;30:627-634.

$>10$ Soong G, Reddy B, Sokol S, Adamo R, Prince A: TLR2 is mobilized into an apical lipid raft receptor complex to signal infection in airway epithelial cells. J Clin Invest 2004;113:14821489.

11 Monick MM, Yarovinsky TO, Powers LS, Butler NS, Carter AB, Gudmundsson G, et al: Respiratory syncytial virus up-regulates TLR4 and sensitizes airway epithelial cells to endotoxin. J Biol Chem 2003;278:5303553044.

12 Beisswenger C, Hess C, Bals R: Aspergillus fumigatus conidia induce interferon- $\beta$ signalling in respiratory epithelial cells. Eur Respir J 2012;39:411-418.

13 Da Silva CA, Hartl D, Liu W, Lee CG, Elias JA: TLR-2 and IL-17A in chitin-induced macrophage activation and acute inflammation. J Immunol 2008;181:4279-4286.

14 John G, Chillappagari S, Rubin BK, Gruenert DC, Henke MO: Reduced surface toll-like receptor-4 expression and absent interferon- $\gamma$ inducible protein-10 induction in cystic fibrosis airway cells. Exp Lung Res 2011;37: 319-326.

15 John G, Yildirim AO, Rubin BK, Gruenert DC, Henke MO: TLR-4-mediated innate immunity is reduced in cystic fibrosis airway cells. Am J Respir Cell Mol Biol 2010;42:424431.

16 Blohmke CJ, Park J, Hirschfeld AF, Victor RE, Schneiderman J, Stefanowicz D, et al: TLR5 as an anti-inflammatory target and modifier gene in cystic fibrosis. J Immunol 2010;185: 7731-7738.

17 Blohmke CJ, Victor RE, Hirschfeld AF, Elias IM, Hancock DG, Lane CR, et al: Innate immunity mediated by TLR5 as a novel antiin- flammatory target for cystic fibrosis lung disease. J Immunol 2008;180:7764-7773.

18 Cosgrove S, Chotirmall SH, Greene CM, McElvaney NG: Pulmonary proteases in the cystic fibrosis lung induce interleukin $8 \mathrm{ex}$ pression from bronchial epithelial cells via a heme/meprin/epidermal growth factor receptor/Toll-like receptor pathway. J Biol Chem 2011;286:7692-7704.

19 Shao MXG, Nadel JA: Neutrophil elastase induces MUC5AC mucin production in human airway epithelial cells via a cascade involving protein kinase $\mathrm{C}$, reactive oxygen species, and TNF-alpha-converting enzyme. J Immunol 2005;175:4009-4016.

20 Bergin DA, Greene CM, Sterchi EE, Kenna C, Geraghty P, Belaaouaj A, et al: Activation of the epidermal growth factor receptor (EGFR) by a novel metalloprotease pathway. J Biol Chem 2008;283:31736-31744.

21 He X, Jing Z, Cheng G: MicroRNAs: New regulators of Toll-like receptor signalling pathways. Biomed Res Int 2014;2014:945169.

22 O'Neill LA, Sheedy FJ, McCoy CE: MicroRNAs: the fine-tuners of Toll-like receptor signalling. Nat Rev Immunol 2011;11:163-175.

23 Lu TX, Munitz A, Rothenberg ME: MicroRNA-21 is up-regulated in allergic airway inflammation and regulates IL-12p35 expression. J Immunol 2009;182:4994-5002.

24 Moschos SA, Williams AE, Perry MM, Birrell MA, Belvisi MG, Lindsay MA: Expression profiling in vivo demonstrates rapid changes in lung microRNA levels following lipopolysaccharide-induced inflammation but not in the anti-inflammatory action of glucocorticoids. BMC Genomics 2007;8:240.

25 Chen Y, Chen J, Wang H, Shi J, Wu K, Liu S, et al: $\mathrm{HCV}$-induced miR-21 contributes to evasion of host immune system by targeting MyD88 and IRAK1. PLoS Pathog 2013; 9:e1003248.
Impact of Dysfunctional microRNA on Innate Immune Responses in the CF Lung 
-26 Sheedy FJ, Palsson-McDermott E, Hennessy EJ, Martin C, O'Leary JJ, Ruan Q, et al: Negative regulation of TLR4 via targeting of the proinflammatory tumor suppressor PDCD4 by the microRNA miR-21. Nat Immunol 2010;11:141-147.

-27 Shin VY, Jin H, Ng EKO, Cheng ASL, Chong WWS, Wong CYP, et al: NF- $\kappa B$ targets miR-16 and miR-21 in gastric cancer: involvement of prostaglandin E receptors. Carcinogenesis 2011;32:240-245.

-28 Arango D, Diosa-Toro M, Rojas-Hernandez LS, Cooperstone JL, Schwartz SJ, Mo X, et al: Dietary apigenin reduces LPS-induced expression of miR-155 restoring immune balance during inflammation. Mol Nutr Food Res 2015;59:763-772.

29 Kuo Y-C, Li Y-SJ, Zhou J, Shih Y-RV, Miller M, Broide D, et al: Human mesenchymal stem cells suppress the stretch-induced inflammatory miR-155 and cytokines in bronchial epithelial cells. PLoS One 2013;8:e71342.

-30 Neagos J, Standiford TJ, Newstead MW, Zeng $\mathrm{X}$, Huang SK, Ballinger MN: Epigenetic regulation of tolerance to Toll-like receptor ligands in alveolar epithelial cells. Am J Respir Cell Mol Biol 2015;53:872-881.

31 Rao R, Nagarkatti P, Nagarkatti M: Staphylococcal enterotoxin B-induced microrna-155 targets SOCS1 to promote acute inflammatory lung injury. Infect Immun 2014;82: 2971-2979.

- 32 McCoy CE, Sheedy FJ, Qualls JE, Doyle SL, Quinn SR, Murray PJ, et al: IL-10 inhibits miR-155 induction by Toll-like receptors. J Biol Chem 2010;285:20492-20498.

- 33 Rao R, Nagarkatti P, Nagarkatti M: Role of miRNA in the regulation of inflammatory genes in staphylococcal enterotoxin B-induced acute inflammatory lung injury and mortality. Toxicol Sci 2015;144:284-297.

-34 Ceppi M, Pereira PM, Dunand-Sauthier I, Barras E, Reith W, Santos MA, et al: MicroRNA-155 modulates the interleukin-1 signaling pathway in activated human monocytederived dendritic cells. Proc Natl Acad Sci USA 2009; 106:2735-2740.

-35 Tang B, Xiao B, Liu Z, Li N, Zhu E-D, Li B-S, et al: Identification of MyD88 as a novel target of miR-155, involved in negative regulation of Helicobacter pylori-induced inflammation. FEBS Lett 2010;584:1481-1486.

- 36 Tili E, Michaille J-J, Cimino A, Costinean S, Dumitru CD, Adair B, et al: Modulation of miR-155 and miR-125b levels following lipopolysaccharide/TNF- $\alpha$ stimulation and their possible roles in regulating the response to endotoxin shock. J Immunol 2007;179:50825089.

37 Xiao B, Liu Z, Li B-S, Tang B, Li W, Guo G, et al: Induction of microRNA-155 during Helicobacter pylori infection and its negative regulatory role in the inflammatory response. J Infect Dis 2009;200:916-925.
38 Saba R, Sorensen DL, Booth SA: MicroRNA146a: a dominant, negative regulator of the innate immune response. Front Immunol 2014; 5:578.

- 39 Comer BS, Camoretti-Mercado B, Kogut PC, Halayko AJ, Solway J, Gerthoffer WT: MicroRNA-146a and microRNA-146b expression and anti-inflammatory function in human airway smooth muscle. Am J Physiol Lung Cell Mol Physiol 2014;307:L727-L734.

- 40 Huang Y, Crawford M, Higuita-Castro N, Nana-Sinkam P, Ghadiali SN: miR-146a regulates mechanotransduction and pressureinduced inflammation in small airway epithelium. FASEB J 2012;26:3351-3364.

-41 Larner-Svensson HM, Williams AE, Tsitsiou E, Perry MM, Jiang X, Chung KF, et al: Pharmacological studies of the mechanism and function of interleukin-1 $\beta$-induced miRNA146a expression in primary human airway smooth muscle. Respir Res 2010;11:68.

42 McMillan DH, Woeller CF, Thatcher TH, Spinelli SL, Maggirwar SB, Sime PJ, et al: Attenuation of inflammatory mediator production by the NF- $\kappa \mathrm{B}$ member RelB is mediated by microRNA-146a in lung fibroblasts. Am J Physiol Lung Cell Mol Physiol 2013; 304:L774-L781.

43 Perry MM, Moschos SA, Williams AE, Shepherd NJ, Larner-Svensson HM, Lindsay MA: Rapid changes in microRNA-146a expression negatively regulate the IL- $1 \beta$-induced inflammatory response in human lung alveolar epithelial cells. J Immunol 2008;180:5689-5698.

44 Zeng Z, Gong H, Li Y, Jie K, Ding C, Shao Q, et al: Upregulation of miR-146a contributes to the suppression of inflammatory responses in LPS-induced acute lung injury. Exp Lung Res 2013;39:275-282.

45 Taganov KD, Boldin MP, Chang K-J, Balti-

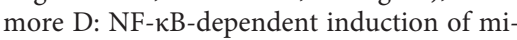
croRNA miR-146, an inhibitor targeted to signaling proteins of innate immune responses. Proc Natl Acad Sci USA 2006;103:1248112486.

46 Yang K, He YS, Wang XQ, Lu L, Chen QJ, Liu J, et al: miR-146a inhibits oxidized low-density lipoprotein-induced lipid accumulation and inflammatory response via targeting Tolllike receptor 4. FEBS Lett 2011;585:854-860.

47 Oglesby IK, Bray IM, Chotirmall SH, Stallings RL, O'Neill SJ, McElvaney NG, et al: miR-126 is downregulated in cystic fibrosis airway epithelial cells and regulates TOM1 expression. J Immunol 1950 2010;184:1702-1709.

48 McKiernan PJ, Greene CM: MicroRNA dysregulation in cystic fibrosis. Mediators Inflamm 2015;2015:529642.

49 Sonneville F, Ruffin M, Guillot L, Rousselet N, Le Rouzic P, Corvol H, et al: New insights about miRNAs in cystic fibrosis. Am J Pathol 2015;185:897-908.

50 Oglesby IK, Agrawal R, Mall MA, McElvaney NG, Greene CM: miRNA-221 is elevated in cystic fibrosis airway epithelial cells and regulates expression of ATF6. Mol Cell Pediatr 2015;2:1.
51 Oglesby IK, Vencken SF, Agrawal R, Gaughan K, Molloy K, Higgins G, et al: miR-17 overexpression in cystic fibrosis airway epithelial cells decreases interleukin-8 production. Eur Respir J 2015;46:1350-1360.

52 Fabbri E, Borgatti M, Montagner G, Bianchi N, Finotti A, Lampronti I, et al: Expression of miR-93 and IL-8 during Pseudomonas aeruginosa-mediated induction of pro-inflammatory responses. Am J Respir Cell Mol Biol 2014; 50:1144-1155.

53 Weldon S, McNally P, McAuley DF, Oglesby IK, Wohlford-Lenane CL, Bartlett JA, et al: miR-31 dysregulation in cystic fibrosis airways contributes to increased pulmonary cathepsin S production. Am J Respir Crit Care Med 2014;190:165-174.

-54 Liljeroos M, Vuolteenaho R, Rounioja S, Henriques-Normark B, Hallman M, Ojaniemi M: Bacterial ligand of TLR2 signals Stat activation via induction of IRF1/2 and interferon-a production. Cell Signal 2008;20:1873-1881.

55 Zhang P-X, Cheng J, Zou S, D’Souza AD, Koff JL, Lu J, et al: Pharmacological modulation of the AKT/microRNA-199a-5p/CAV1 pathway ameliorates cystic fibrosis lung hyperinflammation. Nat Commun 2015;6:6221.

56 Bhattacharyya S, Kumar P, Tsuchiya M, Bhattacharyya A, Biswas R: Regulation of miR-155 biogenesis in cystic fibrosis lung epithelial cells: antagonistic role of two mRNA-destabilizing proteins, KSRP and TTP. Biochem Biophys Res Commun 2013;433:484-488.

57 McKiernan PJ, Cunningham O, Greene CM, Cryan SA: Targeting miRNA-based medicines to cystic fibrosis airway epithelial cells using nanotechnology. Int J Nanomedicine 2013;8:3907-3915.

58 Bhattacharyya S, Balakathiresan NS, Dalgard C, Gutti U, Armistead D, Jozwik C, et al: Elevated miR-155 promotes inflammation in cystic fibrosis by driving hyperexpression of interleukin-8. J Biol Chem 2011;286:1160411615.

59 Cohen TS, Prince AS: Bacterial pathogens activate a common inflammatory pathway through IFN $\lambda$ regulation of PDCD4. PLoS Pathog 2013;9:e1003682.

-60 Vergadi E, Vaporidi K, Theodorakis EE, Doxaki C, Lagoudaki E, Ieronymaki E, et al: Akt2 deficiency protects from acute lung injury via alternative macrophage activation and miR-146a induction in mice. J Immunol 2014;192:394-406.

-61 Liu F, Li Y, Jiang R, Nie C, Zeng Z, Zhao N, et al: miR-132 inhibits lipopolysaccharide-induced inflammation in alveolar macrophages by the cholinergic anti-inflammatory pathway. Exp Lung Res 2015;41:261-269.

62 Wang X, Chen Z: MicroRNA-19a functions as an oncogenic microRNA in non-small cell lung cancer by targeting the suppressor of cytokine signaling 1 and mediating STAT3 activation. Int J Mol Med 2015;35:839-846. 
63 Simpson LJ, Patel S, Bhakta NR, Choy DF, Brightbill HD, Ren X, et al: A microRNA upregulated in asthma airway $\mathrm{T}$ cells promotes TH2 cytokine production. Nat Immunol 2014;15:1162-1170.

64 Shi L, Xin Q, Chai R, Liu L, Ma Z: Ectopic expressed miR-203 contributes to chronic obstructive pulmonary disease via targeting TAK1 and PIK3CA. Int J Clin Exp Pathol 2015;8:10662-10670.

65 Lu L, Zhang X, Zhang B, Wu J, Zhang X: Synaptic acetylcholinesterase targeted by $\mathrm{mi}$ croRNA-212 functions as a tumor suppressor in non-small cell lung cancer. Int J Biochem Cell Biol 2013;45:2530-2540.

-66 Zhang X, Dong C, Sun X, Li Z, Zhang M, Guan Z, et al: Induction of the cellular miR$29 \mathrm{c}$ by influenza virus inhibits the innate immune response through protection of A20 mRNA. Biochem Biophys Res Commun 2014;450:755-761.
67 Li JJ, Tay HL, Maltby S, Xiang Y, Eyers F, Hatchwell L, et al: MicroRNA-9 regulates steroid-resistant airway hyperresponsiveness by reducing protein phosphatase $2 \mathrm{~A}$ activity. J Allergy Clin Immunol 2015;136:462-473.

68 Carraro G, El-Hashash A, Guidolin D, Tiozzo C, Turcatel G, Young BM, et al: miR-17 family of microRNAs controls FGF10-mediated embryonic lung epithelial branching morphogenesis through MAPK14 and STAT3 regulation of E-cadherin distribution. Dev Biol 2009;333:238-250.

69 Zhao D, Zhuang N, Ding Y, Kang Y, Shi L: miR-221 activates the NF- $\kappa$ B pathway by targeting A20. Biochem Biophys Res Commun 2015, Epub ahead of print.

70 Song Q, Li H, Shao H, Li C, Lu X: MicroRNA-365 in macrophages regulates $\mathrm{Myco}$ bacterium tuberculosis-induced active pulmonary tuberculosis via interleukin-6. Int J Clin Exp Med 2015;8:15458-15465.

71 Sharma A, Kumar M, Ahmad T, Mabalirajan U, Aich J, Agrawal A, et al: Antagonism of MMU-miR-106a attenuates asthma features in allergic murine model. J Appl Physiol 2012; 113:459-464.
72 Lan F, Yue X, Ren G, Li H, Ping L, Wang Y, et al: miR-15a/16 enhances radiation sensitivity of non-small cell lung cancer cells by targeting the TLR1/NF- $\kappa \mathrm{B}$ signaling pathway. Int J Radiat Oncol Biol Phys 2015;91:73-81.

73 Ma C, Li Y, Li M, Deng G, Wu X, Zeng J, et al: MicroRNA-124 negatively regulates TLR signaling in alveolar macrophages in response to mycobacterial infection. Mol Immunol 2014; 62:150-158.

74 Zhou X, Li X, Ye Y, Zhao K, Zhuang Y, Li Y, et al: MicroRNA-302b augments host defense to bacteria by regulating inflammatory responses via feedback to TLR/IRAK4 circuits. Nat Commun 2014;5:3619.

75 Xu L, Wen Z, Zhou Y, Liu Z, Li Q, Fei G, et al: MicroRNA-7-regulated TLR9 signaling-enhanced growth and metastatic potential of human lung cancer cells by altering the phosphoinositide-3-kinase, regulatory subunit 3/ Akt pathway. Mol Biol Cell 2013;24:42-55. 